\title{
BMJ Open Associations between primary healthcare and unplanned medical admissions in Norway: a multilevel analysis of the entire elderly population
}

\author{
Trygve S Deraas, ${ }^{1}$ Gro R Berntsen, ${ }^{2}$ Andy $\mathrm{P}$ Jones, ${ }^{3}$ Olav H Førde, ${ }^{4}$ Erik R Sund ${ }^{5}$
}

To cite: Deraas TS,

Berntsen GR, Jones AP, et al. Associations between primary healthcare and unplanned medical admissions in

Norway: a multilevel analysis of the entire elderly population. BMJ Open 2014:4:e004293.

doi:10.1136/bmjopen-2013004293

- Prepublication history for this paper is available online. To view these files please visit the journal online (http://dx.doi.org/10.1136/ bmjopen-2013-004293).

Received 19 October 2013 Revised 19 March 2014 Accepted 20 March 2014

\section{CrossMark}

For numbered affiliations see end of article.

Correspondence to Dr Trygve S Deraas: trygve.deraas@uit.no

\section{ABSTRACT}

Objective: To examine if individual risk of unplanned medical admissions (UMAs) was associated with municipality general practitioner (GP) or long-term care (LTC) volume among the entire Norwegian elderly population.

Design: Cross-sectional population-based study. Setting: 428 of 430 Norwegian municipalities in 2009. Participants: All Norwegians aged $\geq 65$ years ( $n=721915 ; 56 \%$ women- $15 \%$ of the total population).

Main outcome measure: Individual risk of UMA. Results: Using a multilevel analytical framework, consisting of individuals ( $\mathrm{N}=722$ 464) nested within municipalities ( $\mathrm{N}=428)$, nested within local hospital areas $(\mathrm{N}=52)$ we found no association between municipality GP or LTC volume and UMAs. However, we found that higher LTC levels of provision were associated with fewer hospitalisations among the older age groups. A modest geographical variability was observed for UMA in adjusted analysis.

Conclusions: A higher primary healthcare volume was only associated with fewer UMAs among the oldest old in a universally accessible healthcare system.

\section{INTRODUCTION}

Unplanned hospital emergency admissions (UHAs) constitute a significant proportion of overall hospital admissions, and their share has increased in recent years in many advanced societies. ${ }^{1}{ }^{2}$ Although changes from hospital elective activity to outpatient or daytime activity might have contributed to the increase, the observed rise has been of concern for several reasons. First, UHAs are expensive; they encumber hospital planning, disrupt elective care capacity and increase waiting lists. Second, for vulnerable chronically ill elderly patients hospital stays can harm more than they benefit, with risks of medication errors, confusion, hospital infections and over/mistreatment. ${ }^{3}$ Third, it has

\section{Strengths and limitations of this study}

- We analysed complete national data of all unplanned medical admissions among the elderly aged over 65 years.

- A multilevel statistical framework allowed the simultaneous analysis of individual level and higher level predictors.

- Lack of individual-level confounders such as marital status and morbidity, and the study's cross-sectional design precludes any causal interpretation.

been argued that some of these unplanned admissions, especially for non-surgical reasons, may be avoidable or preventable. ${ }^{1}$ Nevertheless, UHA may also be the start of a detailed investigation of the actual clinical problem, which in turn might prevent subsequent hospitalisations. Primary healthcare (PHC) has a theoretical and ideological basis in continuous, person focused, preventive and family/community oriented care, which in many cases cannot be shared by secondary care. ${ }^{4} \mathrm{~A}$ robust and proactive PHC including integrated chronic care and case management could theoretically treat more chronically ill elderly in local settings and prevent some acute crises. This may benefit patients, but the effect on overall costs has not been clarified. ${ }^{56}$

Nevertheless, studies on the relationship between PHC utilisation and unplanned admissions are sparse and conflicting in the evidence they provide. From a methodological perspective they also differ according to age groups, designs and outcomes. Lower UHA rates were associated with higher general practice supply in two studies ${ }^{78}$ and with higher primary care physician density as an indirect measure of PHC in another. ${ }^{9}$ However, it is demonstrated that better access to PHC can increase hospital use among 
some patient populations. ${ }^{10} \mathrm{~A}$ recent British report found no clear association between access to community services and UHA. ${ }^{11}$ Additional services in the PHC might also lead to higher admission rates possibly explained by identification of previously undetected cases. ${ }^{12}$ Analogous to other western countries, a key objective of a recently issued healthcare reform in Norway $^{13}$ was to curb the growth of UHA and more specifically unplanned medical (non-surgical) admissions (UMAs) by shifting resources from specialised healthcare to local PHC. An OECD (Organisation for Economic Co-operation and Development) report from 2006 claimed that insufficient long-term care (LTC) provision in Norwegian municipalities was leading to increased hospitalisations among elderly. ${ }^{14}$ While general practitioners (GPs) are gatekeepers to Norwegian specialist healthcare, as doctors responsible for patient lists covering $99.6 \%$ of the population ${ }^{15}$ and as GPs at out-of-hours casualty clinics, they have up to now had few alternatives to hospital admission in acute cases. This is because municipalities seldom offer emergency care in the LTC setting.

In Norway approximately $70 \%$ of all admissions to hospital are non-elective (not planned), and out of the nonsurgical admissions, nearly $87 \%$ of the admissions are non-elective. ${ }^{16}$ A recent report indicated that, especially among the elderly, much of the geographical variation in hospital use between Norwegian municipalities was linked to unplanned admissions for non-surgical reasons for people aged 80 years and older. ${ }^{17}$ However, we do not know to what extent geographical variation in UMAs arises from differences in the municipality-level provision of PHC.

Geographical variations in healthcare utilisation and spending have been well studied, but there is still controversy regarding whether observed variations arise from differences in supply or need. Ecological studies conflate variation between individuals and variation between geographical units, and multilevel studies are increasingly seen as a methodological advancement in the understanding of geographical variations in healthcare utilisation. ${ }^{18}{ }^{19}$ With a high-quality dataset covering the whole of the population of Norway, we studied within a multilevel statistical framework, associations between two municipality constructs, LTC and GP utilisation, and individuals' likelihood of being hospitalised as a UMA by age. Several studies have argued that local practice ${ }^{20}$ or supply differences ${ }^{21}$ between hospitals may be an additional driver of geographical variation in hospital utilisation. Hence, we also aimed to assess if there was substantial geographical variability in UMAs between municipalities and hospital regions.

\section{METHODS}

\section{Data}

Our analysis was based on a dataset which possessed a three-level hierarchical structure with individuals at the lowest level, which was nested within municipalities (second level) and in hospital regions (third level). The development and nature of this data structure is described below.

The Norwegian Patient Registry (NPR) provided individual-level data on UMAs among individuals aged 65 years and above for the whole of $2009(\mathrm{~N}=120$ 846). These records, which were identified as those that had neither in-stay surgical procedure codes nor surgical discharge diagnoses, were defined as UMAs for the purposes of these analyses. This comprised all UMAs, among individuals aged 65 years and above. The registry only incorporated individuals admitted to a hospital and not the remaining elderly population, but based on Norwegian census information we were able to create an individual-level data structure which represented admissions for the entire elderly population.

As an example of our methodology, if in a particular municipality (a small administrative unit described below) we knew from the census that there were eight women aged between 65 and 69 years and from the NPR we knew that two women had at least one UMA in this particular age group, we created a new data file in which two of these eight municipality residents had at least one UMA event and the remaining six had not. This enabled us to arrive at a data structure which gave an exact representation of the elderly population in individual-level format. By implementing this procedure, our dataset consisted of 120846 hospitalised individuals among the total elderly population of 722464 individuals (aged 65+) where we had information about sex, age group and municipality of residence for the population in 2009.

Our second level of analysis consisted of Norwegian municipalities $(\mathrm{N}=430)$. These are governed by local politicians and they possess some autonomy in terms of welfare arrangements. We had two principal municipality-level predictors of interest. The first, the 'GP consultation rate', was the total number of municipality GP consultations per 1000 inhabitants/year including daytime and out-of-hours service consultations. The second, the LTC rate, refers to the number of recipients of municipality LTC (in home care and community-based residential care homes and nursing homes) per 1000 inhabitants, counted on a specific day each year. Home care recipients make up to $75 \%$ of the LTC users aged $67+$ and get either practical help or nursing care or both. ${ }^{22}$ All LTC is publicly funded, however some services do require copayments. ${ }^{22-24}$ Both predictors were used as proxies for the volume in their respective areas of PHC and they were recoded into four groups (quarters) defined by the quartile cutpoints ranging from Q1 (low) to Q4 (high).

We gathered additional information on municipalitylevel contextual constructs that may confound the association between our main predictors of interest and UMA. One of these was travel time, measured in minutes from the municipality centroid to the nearest hospital with a 
medical emergency department (ED). This covariate was recoded into the following groups: (1) 0-20 min, (2) 20-60 min, (3) 60-120 min and (4) over $120 \mathrm{~min}$. A dummy variable indicating whether the municipality had a hospital with a medical ED was also constructed. Educational level was used as an indicator for area deprivation. This was measured as the mean proportion of the population aged 25 years and older with primary school as the highest educational level in each municipality for the years 2000-2009 and was recoded by the quartile cutpoints. As no municipality-level information on morbidity was available, we used the mean municipality rate of all-cause mortality rate for the years 20002009 as a proxy for morbidity. Mortality is a measure which has been shown to be suitable for this purpose. ${ }^{25}$ This was similarly recoded by the quartile cutpoints. The municipality rate of recipients of disability benefits was also examined as an additional measure of need. The third level of our multilevel framework referred to the local hospital area $(\mathrm{N}=52)$ and contained no predictors. The two principal municipality-level predictors (GP consultation rate and LTC rate) and the municipality-level contextual constructs (travel time, education, all-cause mortality rate and rate of recipients of disability benefits) were collected from Statistics Norway.

\section{Statistical analysis}

For the purpose of analytical efficiency we aggregated the individual-level data to form cells cross tabulated by age group and sex. The outcome for each cell was the proportion of hospitalised individuals for a given age and sex banding. To form this value the numerator was the number of individuals with unplanned hospitalisations and the denominator was the total population used to calculate the proportion of hospitalisations in each cell. This rendered $10(5 \times 2)$ unique groups in which the cell predictor variables related to five age bandings in men and women. These cells were nested within the 430 Norwegian municipalities and 52 local hospital areas. Treating the outcome variable in this way has been shown to produce models that are structurally identical, but computationally more efficient than those that would be generated with individuals at level $1 .^{26-32}$ Using this three-level structure, we applied multilevel models to estimate (1) the contingent relationship between the two municipality constructs (GP and LTC volume) and individual UMA (fixed parameters); (2) the between-municipality and between-hospital region variation that is unaccounted for after adjustment for municipality compositional (case mix) factors (age and sex) and likely confounding covariates (random parameters) and finally (3) how the effect of municipality level of GP and LTC volume varies by age (fixed crosslevel interaction term). The latter construct was based on results from previous ecological studies suggesting that the association between LTC and use of hospital days may be age contingent. ${ }^{33}$ Our response variable, the proportion of the population with at least one UMA in each cell, was modelled using a three-level binomial logit link model with allowances made for varying cell denominator populations. ${ }^{34}$ Fixed and random parameter estimates for the model were calibrated with the penalised quasi-likelihood second order Taylor series expansion routine as implemented within the MLwiN program. ${ }^{35}$ Allowance was made for extrabinomial variation at level 1 (the cell level) since proportions may exhibit more or less variation than a binomial distribution. ${ }^{36}$ Fixed effect estimates are reported as OR with 95\% CI whereas random effects are reported as variances (on the $\log$ odds scale) and median ORs (MORs). ${ }^{37}{ }^{38}$ MOR is defined as the median value of the OR between the area at highest risk and the area at lowest risk. MOR may alternatively be conceptualised as the increased risk, on average, that would result from moving from a lower risk municipality to a higher risk municipality if two municipalities where chosen at random from the distribution within the estimated level 2 variance. We computed the MOR by

$$
\begin{gathered}
\mathrm{MOR}_{\mathrm{HR}} \approx \exp \left(0.95 \sqrt{\sigma_{\mathrm{HR}}^{2}}\right) \\
\mathrm{MOR}_{\mathrm{M}} \approx \exp \left(0.95 \sqrt{\sigma_{\mathrm{HR}}^{2}+\sigma_{\mathrm{M}}^{2}}\right)
\end{gathered}
$$

where $\sqrt{ }$ is the square root of the variance $\left(\sigma^{2}\right)$ at the specific level, $\mathrm{M}=$ municipality, $\mathrm{HR}=$ hospital region. Models were fitted in a sequential manner whereby potential confounders were initially adjusted for, before the exposures of interest were added and their association with our outcome was tested with and without adjustment for the confounders. Finally we examined cross-level interaction terms between age and the two primary predictors.

\section{RESULTS}

Owing to missing covariate information in 2 of the 430 municipalities, we excluded 209 individuals among whom 31 had been hospitalised. Hence, our sample for analysis consisted of 120815 hospitalised individuals among a total population of 722464 individuals nested in 428 municipalities and 52 local hospital areas. Overall a total of 167 per 1000 individuals had at least one UMA during the year (table 1 ).

Men had higher rates of UMA in all age groups, and the rates increased with age for both sexes. Generally there was little variation in UMA rates associated with many of the predictor variables. In particular, the rate of UMAs seemed to vary little by different levels of the LTC rate and GP rate. Fixed effect estimates from multilevel models are depicted in table 2 and we describe them in the order they were estimated. In model 1 , the odds of UMA were found to increase with age. There was an almost fivefold odds (OR=4.89, 95\% CI 4.79 to 5.00$)$ of UMA in the oldest age group (85+ years) compared to the youngest age group and the odds were $29 \%$ higher 
Table 1 Characteristics of the population aged 65 years or older in Norway, 2009

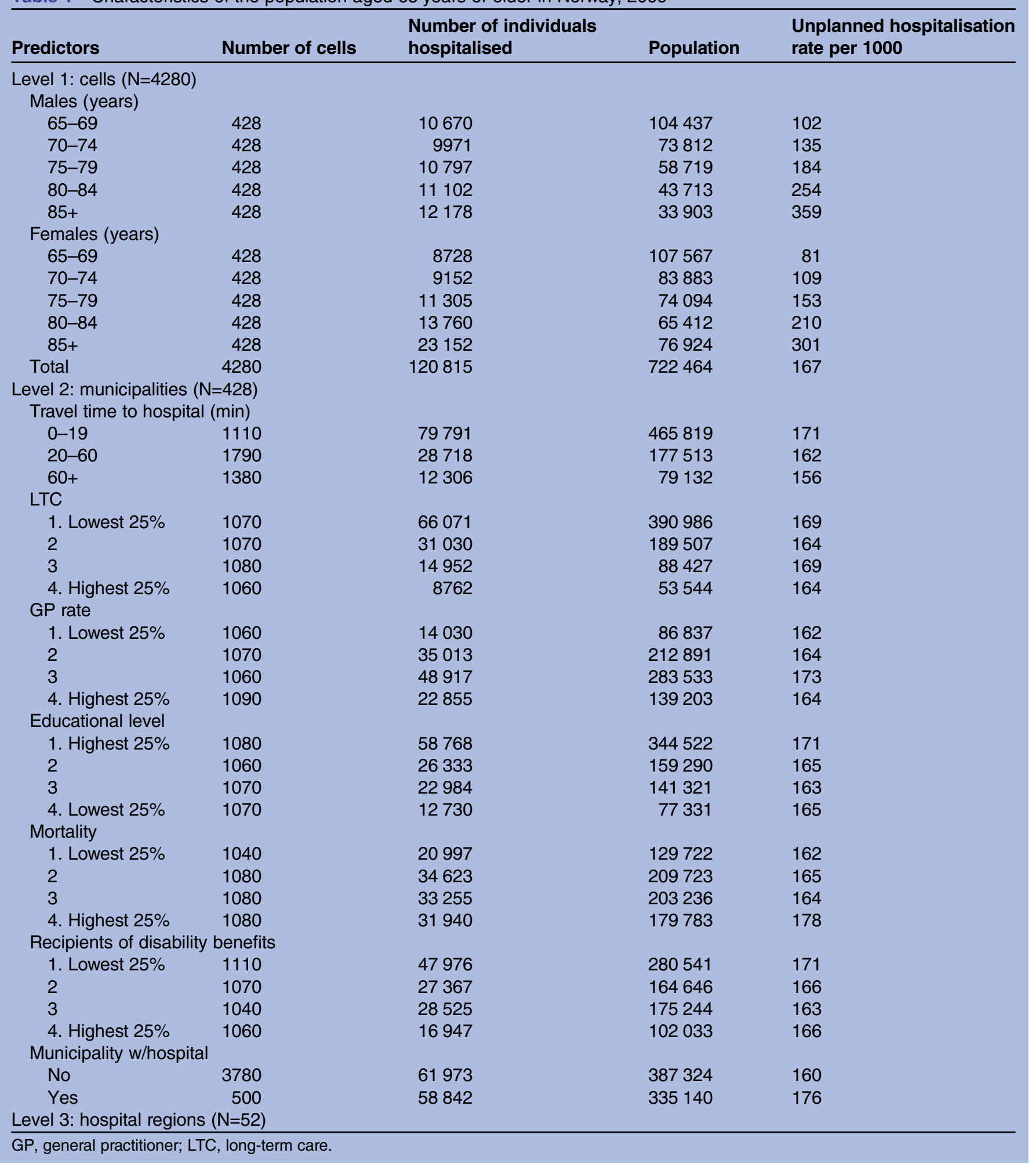

for men compared to women (OR=1.29, 95\% CI 1.27 to 1.30). There was a steady decrease in the odds of UMA by increasing travel time to hospital (model 2). Compared to the reference category the odds were $8 \%$ lower for individuals living in municipalities with a travel time 20-60 min away from hospital and 13\% lower for those in municipalities over 60 min away from hospital.
Municipality LTC level and the 'GP consultation rate' were not associated with UMA whether specified separately (models 4 and 5) or combined (model 6). When we specified models that included the municipality mortality and rates of recipients of disability benefits, the measures were not statistically significant and did not alter associations with our predictors of 
Table 2 Associations (fixed effects) between individual and municipality contextual characteristics and UMAs

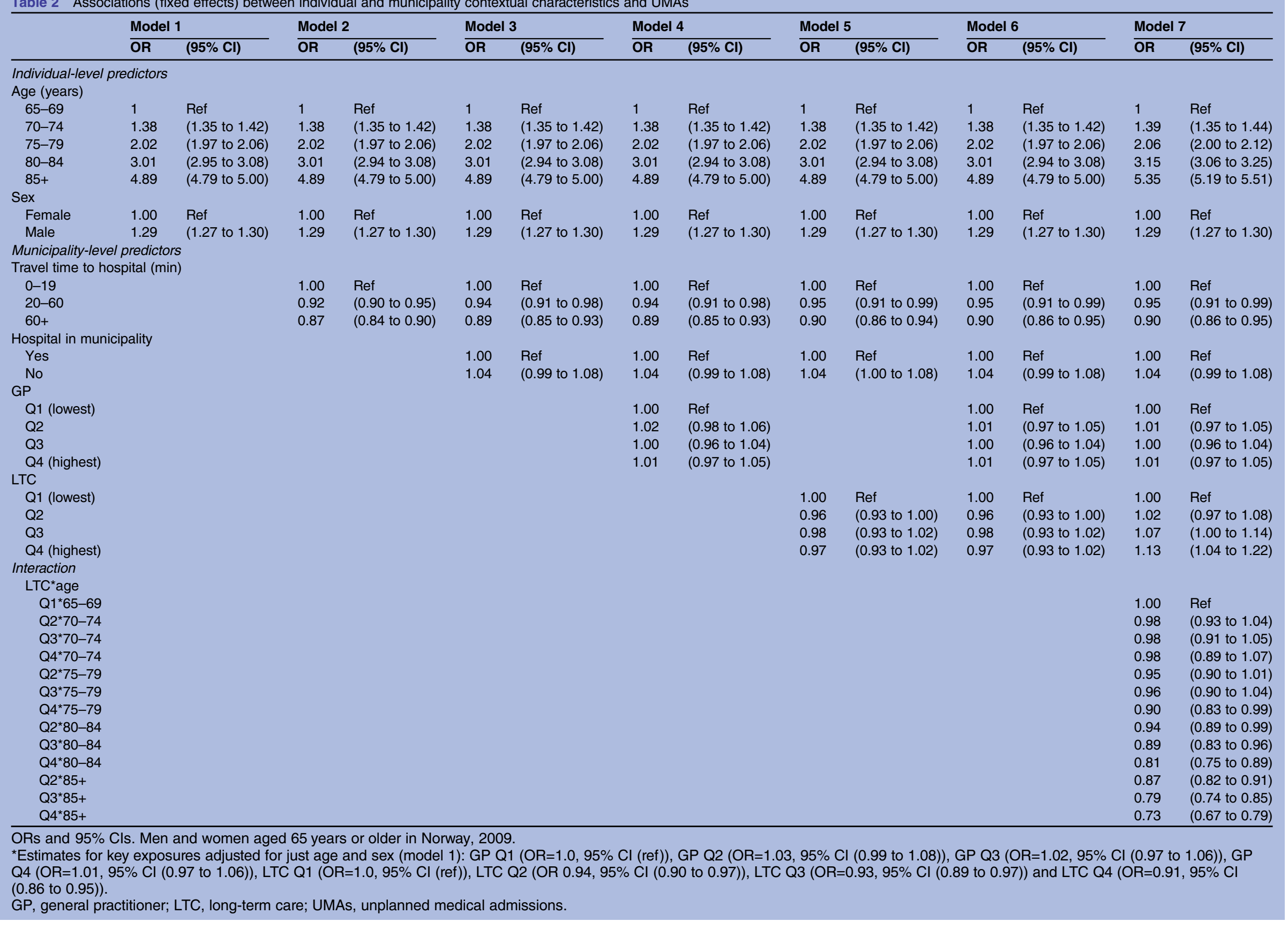

GP, general practitioner; LTC, long-term care; UMAs, unplanned medical admissions. 
interest. Hence, for brevity, we do not show those results.

The ORs for the interaction term between age and LTC in model 7 (which represents the unique additional impact) are visually depicted in figure 1 . It shows differences in log OR for UMA by 'municipality LTC-quarters' $(\mathrm{Q})$ and 'age groups'. For the two youngest age groups (65-69 and 70-74) there was an increase in the probability of UMA by increasing level of LTC, whereas the middle age group (75-79) showed no consistent pattern in any direction. For the two oldest age groups there was a steady and significant decrease in the odds of UMA by increasing level of LTC. An interaction term between age and municipality 'GP consultation rate' was also specified although there was no evidence of any effectmeasure modification (data not shown).

Random effects from the models in table 2 are reported in table 3 as variances (on the log odds scale) and MORs. The between-hospital region variance and the between-municipality variance were somewhat similar, rendering MORs of 1.09 and 1.12, respectively. The variances were significant in all models $(p<0.05)$ and the between-hospital region variance and the betweenmunicipality variance remained stable across models.

\section{DISCUSSION}

The main finding from this work was the lack of an association between the two municipality PHC constructs and UMAs. Overall, neither the municipality 'GP consultation rate' nor the LTC rate was associated with the

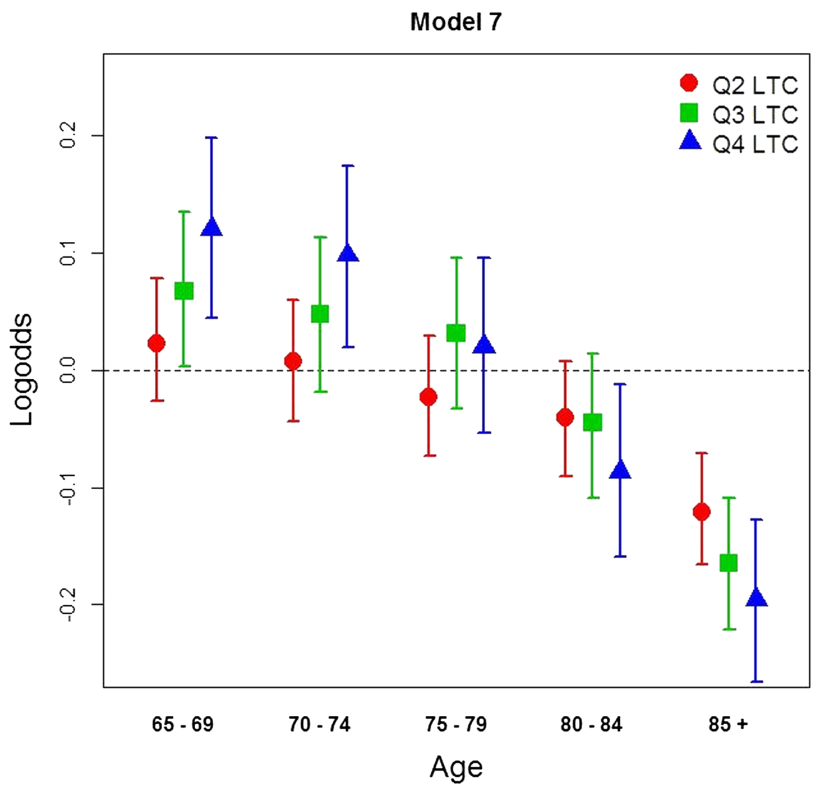

Figure 1 Predicted differences (log OR) of UMAs by LTC quartiles and age group (model 7 ). Men and women aged 65 years and older, Norway, 2009. Reference category in each age group are individuals living in municipalities with the lowest LTC level (Q1 LTC; log odds $=0$, dashed line). LTC, long-term care; UMAs, unplanned medical admissions.

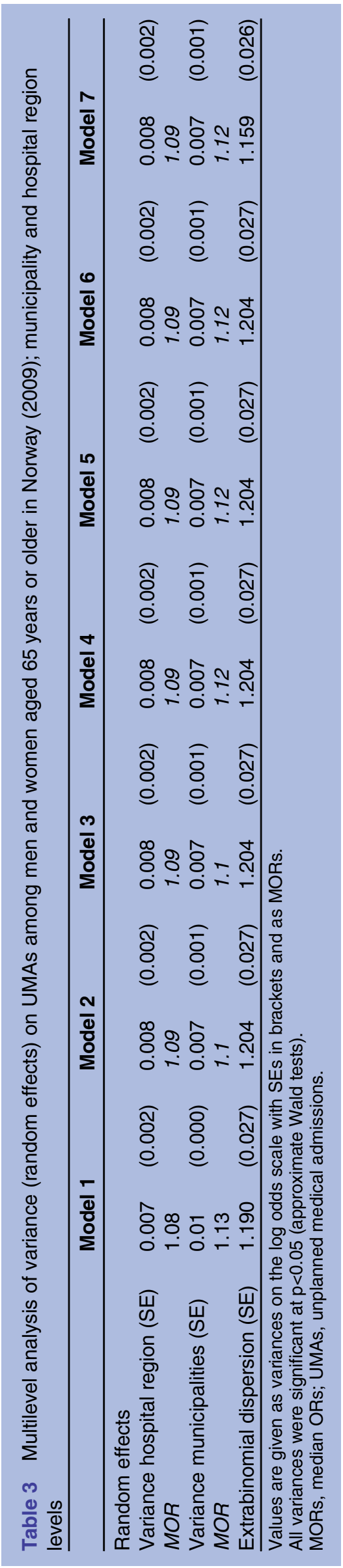


probability of UMAs occurring. However, the inclusion of the cross-level interaction term between age and LTC rate provided some evidence to suggest that the level of LTC provision may be of importance in preventing UMAs among the oldest age groups, whereas the opposite pattern was found for the two youngest age groups. After adjustment the remaining geographical variability in UMAs was modest at both the municipality level as well as at the local hospital area level.

As discussed in the introduction to this article, findings from previous international studies are inconsistent regarding the association between LTC use and acute use of hospitals. Previous research is also ambiguous with respect to the effect GP volume may have on unplanned hospitalisations. It may be that discrepancies between different welfare regime types in terms of their health and social care systems are limiting the generalisability of findings from one regime type to another. Indeed, one review has shown that studies from the USA tend to be supportive of the assumption that more PHC is associated with less hospitalisation, while those from the UK are compatible with the present findings. ${ }^{39} 40$ The authors of the review argue that in a universally accessible healthcare system, a 'ceiling' may be present beyond which additional primary care does not have the desired consequences in terms of reduced hospitalisations. In Norway, there is full GP coverage and fewer patients per GP than in UK, ${ }^{15}{ }^{41}$ and the formal LTC coverage is among the highest in Europe. ${ }^{42}$ Our findings might therefore indicate presence of the same phenomenon.

We found that the relationship between LTC and UMA varied across age groups. This might partly be explained by less informal care, as more elderly live alone and LTC has to substitute for informal care. It may also reflect changing evaluations with age, that is, a particular condition (eg, pneumonia) may be the reason for a UMA in a younger patient, whereas the same condition may not cause further medical examination in hospital for an elderly patient with dementia. A likely methodological artefact refers to the fact that the municipality LTC rate to some extent is correlated with municipality mean age among the elderly (Pearson correlation coefficient $=0.5$ ). We did find a distance decay effect between UMA rates and travel time to the nearest hospital, something others have noted. Indeed a distance decay effect is especially important for individuals with restricted physical mobility such as many elderly, ${ }^{43}$ and a Canadian study found a lower referral rate in rural areas. ${ }^{44}$ We did not find different levels of UMAs for people from hospital municipalities versus those without a hospital. Models with and without random effects for hospital areas were specified but had no effect on the fixed effect estimates. This suggests no clustering of low or high GP consultation rate/LTC rate municipalities in low admission hospital areas.

When we examined the effect of our proxies for morbidity, namely municipality rates of mortality and rates of recipients of disability benefits, we found no influence on the associations with primary care provision. Hence, it does not seem that the municipality level of need, at least based on our measures, is an important confounder. This conclusion is in line with a Dutch multilevel study where the municipality-level characteristics did not influence ED utilisation. ${ }^{45}$ We found a moderate positive correlation between GP consultation rate and mortality (Pearson coefficient 0.42) and a weak positive correlation between LTC and mortality (Pearson coefficient $0.20)$ which suggests that provision is weakly associated with need rather than service standards.

In terms of study strengths, we had data on all UMAs in Norway through 1 year, among all Norwegians aged 65 years and older. The analyses were undertaken within a multilevel framework with an ecological perspective which allowed us to address our primary interest which concerned municipality contextual constructs and their influence in individuals' likelihood of being hospitalised at the same time as considering geographical variability between multiple levels of nesting. ${ }^{46}$ This is an advancement compared to a purely ecological or aggregate study which by definition conflates the compositional with the contextual. ${ }^{19}$

Our outcome measure, UMA, is used for financial reimbursements and is hence checked by hospitals and the NPR. GP consultation data are obligate for financial reimbursement from Norwegian Health Economics Administration (HELFO). Therefore, we also believe we have almost complete GP consultation data. The private LTC sector in Norway is minimal, so the data on municipal LTC includes almost all recipients. The LTC data have been through an internal quality check mainly based on comparison with previous year's data and internal consistency. As the Norwegian healthcare system has no private hospitals with emergency services, the relationship between PHC and UMA is studied in a homogeneous public financed healthcare system and has transferability to similar welfare state typologies.

Our primary interest was to examine the association between the volume of PHC and the propensity for UMA. Other authors have limited similar analysis to unplanned admissions for 'ambulatory care sensitive conditions' (ACSCs). For several reasons, we are not convinced that such limitation is superior to our analysis which included unplanned admissions for all "nonsurgical' conditions. The concept of ACSCs was developed as an indirect indicator of local PHC access in the $\mathrm{USA}^{47}$ and is not consistently defined around the world. It is often linked to the purpose and healthcare system it is studied in. ${ }^{48}{ }^{49}$ Further, analysing of admissions based on diagnoses at discharge without including information at admission might lead to misclassifications and erroneous conclusions about the potential role of PHC and enlarge the proportion of inappropriate admissions. In a recent American study, when ED visits categorised as 'primary-care treatable' at discharge were assessed with information on main complaint presented at admission, only $6 \%$ remained as 'primary care treatable'. 
There are some limitations to our analysis. We have analysed all UMAs rather than only those among patients with frequent admission, and our outcome measure cannot differentiate between situations whereby many patients have few UMAs or a few patients have many. However, we have no reason to believe that the potentially preventive effect of the PHC would be different for people being hospitalised once compared to those being hospitalised several times, especially as it has been demonstrated that frequent users of ED also are heavy users of other healthcare services. ${ }^{51}$ Further, a recent review concluded that frequent users are heterogeneous, relatively few and unlikely to be the main contributors to the growth in UMAs. ${ }^{52}$

The cross-sectional design with data for a single year limits our ability to ascribe causality to the associations we observed. There is a possibility that we have been unable to capture all of the individual-level factors that are associated with UMAs. Specifically, the unavailable individual data on marital status and morbidity may be important. In the oldest age groups more people are likely to be singleton households with less availability of informal care from spouses, and individuals living alone are more likely to be hospitalised. ${ }^{53}$

It is possible to overcome some of the limitations in the present study, and this should be pursued in further research. Utilisation of total population health survey data (eg, the HUNT and Troms $\varnothing$ studies) $)^{54} 55$ with a linkage to existing hospital patient data and administrative registry data is possible since every citizen in Norway has a unique identification code. This would enable us to adjust for need at the individual level. Nevertheless, these population surveys are less heterogeneous because they only cover small regions, while the present work covers the entire country. Furthermore, linkage between individual PHC data and specialist healthcare data is currently not possible.

\section{CONCLUSION}

Our analyses did not support the assumption that a higher PHC volume will reduce pressure on ED in a universal healthcare system. However, higher municipality LTC volume was associated with less UMAs among the oldest. A low level of variability among municipalities and hospital regions suggested that place of residence was of minor importance for the individual's risks for UMA.

\footnotetext{
Author affiliations

${ }^{1}$ Center of Clinical Documentation and Evaluation, Northern Norway Regional Health Authority, Box 6, N-9038 Tromsø, Norway

${ }^{2}$ Norwegian Centre for Integrated Care and Telemedicine, University Hospital of North Norway, Tromsø, Norway

${ }^{3}$ Faculty of Medicine and Health Sciences, Norwich Medical School, University of East Anglia, Norwich, UK

${ }^{4}$ Department of Community Medicine, University of Tromsø, Tromsø, Norway ${ }^{5}$ Department of Public Health and General Practice, Faculty of Medicine, HUNT Research Centre, Norwegian University of Science and Technology, Levanger, (NTNU), Norway
}

Acknowledgements The authors are thankful to Bård Uleberg and Ina Heiberg, for their participation in collecting and checking of the data, and to Alexander Walnum, for figure art work.

Contributors TSD and ERS designed the study and the analysis. ERS and TSD carried out the analysis and TSD drafted the first version of the paper and is the guarantor of the study. All authors contributed to the interpretation and writing of the paper and have reviewed and approved the final version.

Funding The Regional Health Authority of Northern Norway and the National Centre for Rural Medicine have partly funded the study.

Competing interests None.

Ethics approval This study was initially approved by the Privacy Ombudsman for Research in Norway in accordance with the Personal Data Act and Health Registry Act (project number 17869). It is also part of a larger project ('Analyses of patient trajectories') which has been approved by Regional Committee for Medical and Health Research Ethics in Northern Norway (REK nord) and the Norwegian Data Protection Authority.

Provenance and peer review Not commissioned; externally peer reviewed.

Data sharing statement The dataset on which the analyses were performed can be obtained from the corresponding author, while the raw dataset is not available due to Norwegian privacy regulations. Applicants must be prepared to conform to Norwegian privacy regulations.

Open Access This is an Open Access article distributed in accordance with the Creative Commons Attribution Non Commercial (CC BY-NC 3.0) license, which permits others to distribute, remix, adapt, build upon this work noncommercially, and license their derivative works on different terms, provided the original work is properly cited and the use is non-commercial. See: http:// creativecommons.org/licenses/by-nc/3.0/

\section{REFERENCES}

1. Blunt I, Bardsley M, Dixon J. Trends in emergency admissions in England 2004-2009. Nuffield Trust: Nuffield Trust, 2010.

2. Pitts SR, Pines JM, Handrigan MT, et al. National trends in emergency department occupancy, 2001 to 2008: effect of inpatient admissions versus emergency department practice intensity. Ann Emerg Med 2012;60:679-86.

3. Covinsky KE, Pierluissi E, Johnston CB. Hospitalization-associated disability: 'She was probably able to ambulate, but l'm not sure'. JAMA 2011;306:1782-93.

4. Starfield B. Primary care: balancing health needs, services, and technology. 1st edn. Oxford University Press, 1998.

5. Reid RJ, Coleman K, Johnson EA, et al. The group health medical home at year two: cost savings, higher patient satisfaction, and less burnout for providers. Health Aff 2010;29:835-43.

6. Kringos DS, Boerma W, van der Zee J, et al. Europe's strong primary care systems are linked to better population health but also to higher health spending. Health Aff 2013;32:686-94.

7. Rosenblatt RA, Wright GE, Baldwin LM, et al. The effect of the doctor-patient relationship on emergency department use among the elderly. Am J Public Health 2000;90:97-102.

8. Ionescu-Ittu R, McCusker J, Ciampi A, et al. Continuity of primary care and emergency department utilization among elderly people. CMAJ 2007; 177:1362-8.

9. Kravet SJ, Shore AD, Miller R, et al. Health care utilization and the proportion of primary care physicians. Am J Med 2008;121:142-8.

10. Saha S, Solotaroff R, Oster A, et al. Are preventable hospitalizations sensitive to changes in access to primary care? The case of the Oregon Health Plan. Med Care 2007;45:712-19.

11. Imison C, Poteliakhoff E, Thompson J. Older people and emergency bed use. Exploring variation. London: King's Fund, 2012.

12. Gravelle H, Dusheiko M, Sheaff R, et al. Impact of case management (Evercare) on frail elderly patients: controlled before and after analysis of quantitative outcome data. BMJ 2007;334:31.

13. Norwegian Ministry of Health and Care services. The coordination reform: proper treatment-at the right place and right time (English). http://www.regjeringen.no/nb/dep/hod/dok/regpubl/stmeld/20082009/stmeld-nr-47-2008-2009-.html?id=567201

14. Bibbee A, Padrini F. Balancing health care quality and cost containment: the case of Norway. OECD Publishing, 2006. Report No.: 481.

15. Gaardsrud PØ. [Management data for GP scheme, 4 quarter of 2011]. Norwegian Directorate of Health, 2012. 
16. Norwegian Directorate of health. [SAMDATA — specialized health care 2011]. 2012

17. Heiberg I. [Hospital utilization in hospital municipalities]. Center of Clinical Documentation and Evaluation, 2010.

18. Subramanian SV, Jones K, Duncan C. Multilevel methods for public health research. In: Kawachi I, Berkman LF. eds Neighborhoods and health. New York: Oxford University Press, 2003:65-111.

19. Moon G, Subramanian SV, Jones K, et al. Area-based studies and the evaluation of multilevel influences on health outcomes. In: Bowling AESE. ed Handbook of health research methods: investigation, measurement and analysis. Maidenhead. Open University Press, 2005:266-92.

20. Sirovich B, Gallagher PM, Wennberg DE, et al. Discretionary decision making by primary care physicians and the cost of U.S. Health care. Health Aff (Millwood) 2008;27:813-23.

21. Fisher ES, Wennberg DE, Stukel TA, et al. The implications of regional variations in Medicare spending. Part 1: the content, quality, and accessibility of care. Ann Intern Med 2003;138:273-87.

22. Huseby BM, Paulsen B. [Elderly care in Norway: totally inadequateor the best in the world?]. SINTEF Health Services Research, 2009.

23. Statistics Norway. [Seniors in Norway 2010. Statistical analyses 120] Seniorer i Norge 2010. Statistiske analyser 120. Statistics Norway, 2011. http://www.ssb.no/emner/00/02/sa_seniorer/sa120/kap8.pdf

24. The Commonwealth Fund. International profiles of health care systems, 2011. The Commonwealth Fund, 2012.

25. Mays N. Measuring morbidity for resource allocation. BMJ (Clin Res Ed) $1987 ; 295: 703-6$.

26. Goldstein $\mathrm{H}$. Multilevel modelling of survey data*. Statistician 1991;40:233-44.

27. Subramanian SV, Duncan C, Jones K. Multilevel perspectives on modeling census data. Environ Plann A 2001;33:399-417.

28. Subramanian SV, Chen JT, Rehkopf $\mathrm{DH}$, et al. Racial disparities in context: a multilevel analysis of neighborhood variations in poverty and excess mortality among black populations in Massachusetts. Am J Public Health 2005;95:260-5.

29. Moon G, Barnett R, Pearce J. Ethnic spatial segregation and tobacco consumption: a multilevel repeated cross-sectional analysis of smoking prevalence in urban New Zealand, 1981-1996. Environ Plann A 2010;42:469-86.

30. Jones K, Subramanian SV. Developing multilevel models for analysing contextuality, heterogeneity and change. Volume 2. UK: University of Bristol. 2012.

31. Suzuki E, Kashima S, Kawachi I, et al. Social and geographic inequalities in premature adult mortality in Japan: a multilevel observational study from 1970 to 2005. BMJ Open 2012;2:e000425.

32. Suzuki E, Kashima S, Kawachi I, et al. Geographic inequalities in all-cause mortality in Japan: compositional or contextual? PLoS ONE 2012;7:e39876.

33. Deraas T, Berntsen G, Hasvold T, et al. Does long-term care use within primary health care reduce hospital use among older people in Norway? A national five-year population-based observational study. BMC Health Serv Res 2011;11:287.

34. Goldstein H. Multilevel statistical models. 3rd edn. London: Edward Arnold, 2003.

35. MLwiN Version 2.1. [computer program]. Centre for Multilevel Modelling, University of Bristol, 2009.
36. Collett D. Modelling binary data. 2nd edn. London: Chapman and Hall, 1991

37. Larsen $\mathrm{K}$, Petersen JH, Budtz-Jorgensen $\mathrm{E}$, et al. Interpreting parameters in the logistic regression model with random effects. Biometrics 56, 909-914. Biometrics 2000;56:909-14.

38. Larsen $\mathrm{K}$, Merlo J. Appropriate assessment of neighborhood effects on individual health: integrating random and fixed effects in multilevel logistic regression. Am J Epidemiol 2005;161:81-8.

39. RAND Europe, Ernst \& Young, University of Cambridge. Nationa evaluation of the Department of Health's Integrated Care Pilots, Final Report. UK: Department of Health, 2012.

40. Roberts E, Mays N. Can primary care and community-based models of emergency care substitute for the hospital accident and emergency (A \& E) department? Health Policy 1998;44:191-214.

41. Gulliford MC. Availability of primary care doctors and population health in England: is there an association? J Public Health 2002;24:252-4.

42. Organisation for Economic Co-operation and Development. Health at a glance 2011: OECD indicators. OECD Publishing, 2011.

43. Curtis S. Health and inequality. 2nd edn. London: SAGE Publications, 2004.

44. Chan BT. Patient, physician, and community factors affecting referrals to specialists in Ontario, Canada: a population-based, multi-level modelling approach. Med Care 2003;41:500-11.

45. Demaerschalk MF, Vanden Boer LE, Bronselaer JL, et al. The influence of municipal characteristics on the use of informal home care and home care services by the elderly Flemish. Eur J Public Health 2013;23:241-6.

46. Greenland S. Ecologic versus individual-level sources of bias in ecologic estimates of contextual health effects. Int $\mathrm{J}$ Epidemiol 2001;30:1343-50.

47. Billings J, Zeitel L, Lukomnik J, et al. Impact of socioeconomic status on hospital use in New York City. Health Aff 1993;12: 162-73.

48. Bardsley M, Blunt I, Davies S, et al. Is secondary preventive care improving? Observational study of 10 -year trends in emergency admissions for conditions amenable to ambulatory care. BMJ Open 2013:3:pii: e002007.

49. Purdy S. Avoiding hospital admissions, what does the research evidence say? King's Fund, 2010.

50. Raven MC, Lowe RA, Maselli J, et al. Comparison of presenting complaint vs discharge diagnosis for identifying ' nonemergency' emergency department visits. JAMA 2013;309:1145-53.

51. Hansagi $\mathrm{H}$, Olsson $\mathrm{M}$, Sjoberg $\mathrm{S}$, et al. Frequent use of the hospital emergency department is indicative of high use of other health care services. Ann Emerg Med 2001;37:561-7.

52. LaCalle E, Rabin E. Frequent users of emergency departments: the myths, the data, and the policy implications. Ann Emerg Med 2010;56:42-8.

53. Aliyu MH, Adediran AS, Obisesan TO. Predictors of hospital admissions in the elderly: analysis of data from the longitudinal study on aging. J Natl Med Assoc 2003;95:1158-67.

54. Krokstad S, Langhammer A, Hveem K, et al. Cohort profile: the HUNT study, Norway. Int J Epidemiol 2013;42:968-77.

55. Jacobsen BK, Eggen AE, Mathiesen EB, et al. Cohort profile: the Tromsø Study. Int J Epidemiol 2012;41:961-7. 